\title{
Effect of a "stop smoking" booklet on smokers attending for chest radiography: a controlled study
}

\author{
IA CAMPBELL, MARGARET HANSFORD, RJ PRESCOTT
}

From Sully Hospital, Cardiff and the Medical Computing and Statistics Unit, University of Edinburgh Medical School, Edinburgh

ABSTRACT At two chest clinics 1206 cigarette smokers referred by their general practitioners for chest radiography only either were dealt with in the normal way or in addition were given a How to Stop Smoking booklet by the clinic receptionist or nurse. Follow up one year later showed that $3.2 \%$ of all patients had successfully given up smoking, older patients doing better than younger ones and men doing better than women. Overall $3.9 \%$ of the group receiving a booklet were successful compared with $2.7 \%$ of the controls $(p=0.14)$. At one clinic the groups were not well matched for age but at the other, where there was no such imbalance, there was a suggestion that the booklet group did better than the controls $(6.5 \% \vee 2.7 \%$ success), although the difference did not achieve conventional statistical significance $(p=0.09)$. If this can be confirmed as a real effect then this cheap, simple strategy could easily be applied on a large scale.

Smokers referred to a chest clinic or to hospital for a chest radiograph are likely to be concerned about their health and may be more open than usual to advice about giving up smoking. We have tested the value of giving them a simple, cheap booklet at the time of radiography. The pocket sized booklet, 13 pages long, stated the dangers of smoking and the real health benefit of giving up, made simple suggestions on how to set about stopping smoking, and gave advice on how to remain without cigarettes. The booklet contained answers to common queries patients have about stopping smoking, as well as a table for reckoning the financial savings of stopping. It recommended that the smoker should stop completely rather than cut down gradually, emphasising that determination and being prepared for difficulties were vital to success.

\section{Methods}

At two chest clinics in South Wales patients referred by their general practitioner for chest radiography were asked about smoking by the receptionist or clinic nurse. Cigarette smokers were then either radiographed as usual or radiographed and given a booklet

Address for reprint requests: Dr IA Campbell, Sully Hospital, Cardiff CF6 2YA.

Accepted 11 November 1985 by the same staff. The two strategies alternated fortnightly. Sex, age, number of cigarettes smoked daily, and occupation were recorded in the normal way. A note was made of whether the patient was later recalled for a clinical consultation because of the result of the radiograph. One year later a letter was sent from the clinic to the patient inquiring whether he or she had stopped smoking and, if so, when. A stamped, addressed envelope in which to return the answer slip was enclosed. Those not replying were sent two further inquiries; if no reply was received that patient was classed as a smoker. Patients who claimed to be non-smokers and not to have smoked for the previous six months were asked to attend for a "breathing test." Expired air carbon monoxide was measured (Exhaled Carbon Monoxide Monitor, GMI Medical Ltd) to check the veracity of the patients' statements and a concentration of more than $10 \mathrm{ppm}$ taken to indicate current smoking. ${ }^{12}$ If the non-smoking claim was verified the patient was deemed a success. Those who failed to attend were invited again on two further occasions and were classified as smokers if they never attended.

\section{Results}

Of the 1206 individuals entering the study (table), 535 received the booklet and 671 did not. The smaller size of the group having the booklet was due to the closure 
Details of patients subdivided by centre attended, sex, and age and whether a booklet was issued (figures divided by a colon are for the group receiving and the group not receiving the booklet)

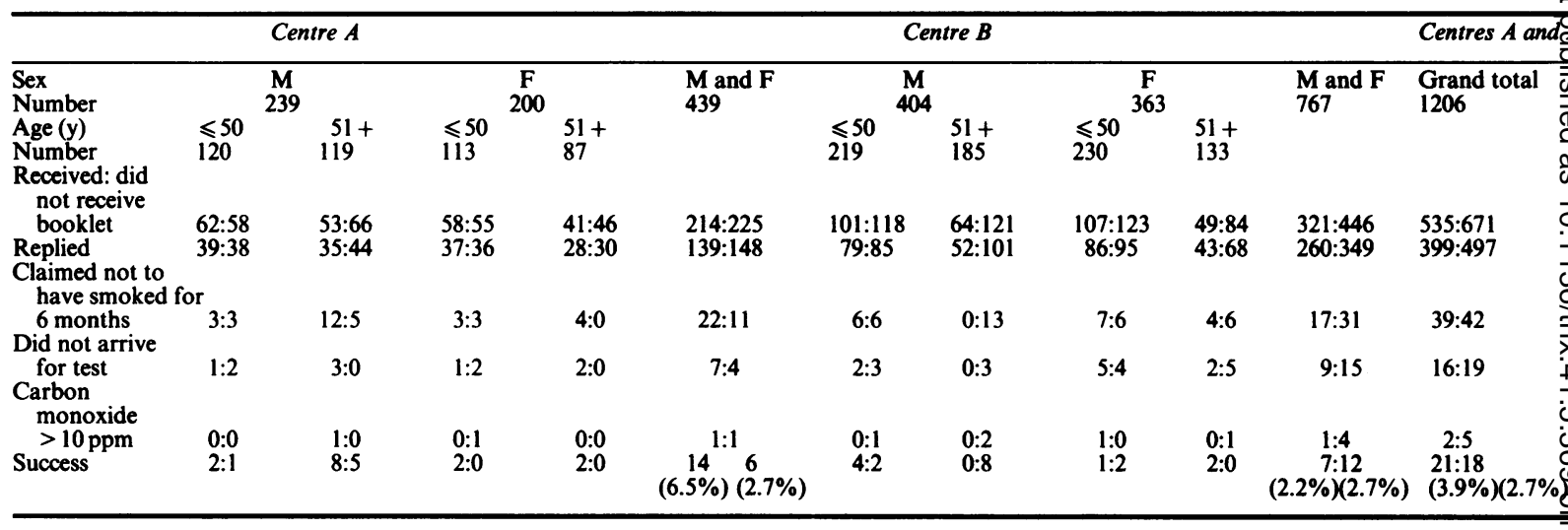

of centre B's radiograph unit because of equipment breakdown during two periods when booklets would have been issued in the winter months. The groups were well matched for sex, cigarette consumption, social class, rate of recall to clinic, and reply rate; but $33 \%$ of the booklet group were aged 51 and over compared with $47 \%$ of the controls $\left(\chi^{2}{ }_{c}=8.5\right.$, $\mathrm{p}=0.004$ ).

At one year replies were received from 896 subjects (74.3\%), of whom 81 claimed not to have smoked for six months. Thirty five of these patients did not attend for the expired air carbon monoxide test; of the $\mathbf{4 6}$ patients who attended, seven had more than $10 \mathrm{ppm}$ of carbon monoxide in their expired air.

The overall success rate was $3.2 \%$. A linear logistic regression model was used to investigate the relationship of other variables to the probability of success. This showed a significant effect of age (those aged 50 years or less had a $2.1 \%$ success rate whereas those over 50 years had a $6.9 \%$ success rate $(p=0.02)$. Men had a higher success rate than women $(4.7 \% v 1.4 \% ; \mathrm{p}=0.004)$. There was no statistical difference between attenders at the two centres (A $4.6 \%$ success $v$ B $2.5 \% ; \mathrm{p}=0.08$ ). The success rate for stopping smoking did not differ significantly between those who received and those who did not receive the booklet $(3.9 \% v 2.7 \% ; p=0.14)$. Social class, daily cigarette consumption, and whether the patient had been recalled to the clinic had no discernible effect on the probability of success. There was a suggestion (table) that the booklet had been more successful in centre $A$ than in centre $B$, where there had been a breakdown of equipment. This "treatment by centre" interaction was not, however, significant $(p=0.10)$, and the results from centre $A$ alone did not show a treatment effect significant at conventional levels $(p=0.09)$.

\section{Discussion}

In the case of patients, previous studies have suggested that written advice, with or without a warning of follow up, can add to the effectiveness of a general practitioner's oral advice about giving up smoking. ${ }^{34}$ Ledwith demonstrated a useful effect when smokers responding to a newspaper advertisement offering help were sent a leaflet. ${ }^{5}$ In our study it is possible that the overall success rate was underestimated $\overrightarrow{\vec{B}}$ because those who did not attend for the test have all been classed as smokers: attendance required a special journey to the clinic and this might have deterred some patients who were in fact not smoking.

We have not been able to demonstrate a clear effect of a booklet given by the receptionist or nurse to smokers attending chest clinic just for a chest radiograph. The group receiving the booklet contained fewer older patients, an imbalance stemming entirely from centre B. At centre A, where no such imbalance occurred, there was a suggestion that the booklet $O$ might have had an effect, although the probability of such a difference occurring by chance was around one in 10. If this suggestion is confirmed as a real effect $\vec{N}$ then this method, which is inexpensive in terms of $\sigma$ manpower, time, and materials, could easily be $N$ applied on a large scale.

We are grateful to the Cancer Research Campaign for funding the study. We thank Sister Jill Williams and $\stackrel{?}{+}$ Mrs Ruth James for their invaluable help and Drs $G$ Anderson and G Chappell for their cooperation.

Further information about the booklet is available from $\mathrm{Dr}$ Campbell. In 1982 the cost was about 6p a copy. 


\section{References}

1 Jarvis MJ, Russell MAH, Saloojee Y. Expired air carbon monoxide: a simple breath test of tobacco smoke intake. Br Med J 1980;281:484-5.

2 Saloojee Y, Vesey CJ, Cole PV, Russell MAH. Carboxyhaemoglobin and plasma thiocyanate: complementary indicators of smoking behaviour? Thorax 1982;37:521-5.

3 Russell MAH, Wilson C, Taylor C, Baker CD. Effect of general practitioners' advice against smoking. $\mathrm{Br}$ Med J 1979;ii:231-5.

4 Jamrozik K, Vessey M, Fowler G, Wald N, Parker G, Van Vunakis $\mathbf{H}$. Controlled trial of three different antismoking interventions in general practice. $\mathrm{Br}$ Med $\mathrm{J}$ 1984;288:1499-503.

5 Ledwith F. Immediate and delayed effect of postal advice on stopping smoking. Health Bull (Edinb) 1984;42: 332-44. 